\title{
Grupos de discussão virtual: \\ uma proposta para \\ o ensino em enfermagem*
}

\author{
VIRTUAL DISCUSSION GROUPS: A PROPOSAL FOR NURSING TEACHING \\ GRUPOS DE DISCUSIÓN VIRTUAL: UNA PROPUESTA PARA LA ENSEÑANZA EN ENFERMERÍA
}

Daiane Dal Pai', Liana Lautert ${ }^{2}$

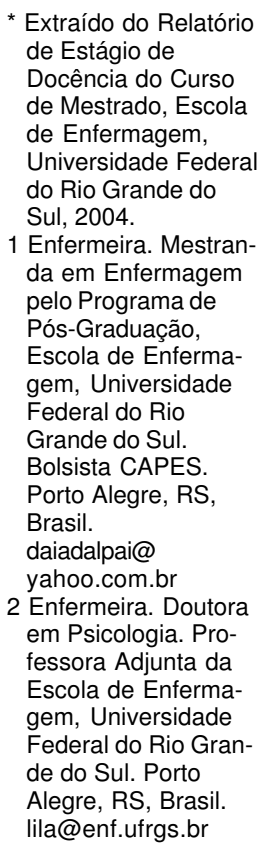

\begin{abstract}
RESUMO
Este trabalho descreve uma experiência docente que teve como objetivo proporcionar interatividade à técnica do diário de campo, utilizando um ambiente virtual de aprendizagem. A proposta educacional teve como origem o Estágio de Docência, vinculado ao Programa de Pós-Graduação Stricto Sensu em Enfermagem da Universidade Federal do Rio Grande do Sul (UFRGS), no qual a mestranda, supervisionada pela sua orientadora, propôs a formação de grupos de discussão virtual para realizar o diário de campo em uma disciplina da graduação em enfermagem, visando a oportunizar a discussão conjunta das vivências acadêmicas em campo de prática. Os professores da disciplina na qual a proposta foi desenvolvida também estiveram inseridos nas atividades. A tecnologia virtual dinamizou a técnica de diário de campo, permitindo a troca de experiências entre os acadêmicos, o professor e a mestranda, assim como momentos de reflexão e discussão acerca dos temas confrontados na prática da

\section{ABSTRACT}

This paper describes a teaching experience aimed at providing interactivity to the technique of field diary by using a virtual learning environment. The educational proposal derives from the Federal University of Rio Grande do Sul (UFRGS)'s Teaching Training Program of the Stricto Sensu Post-Graduation Program in Nursing, in which the author, a Master's degree candidate, oriented by her advisor, proposed forming virtual discussion groups in order to write the field diary for an undergraduate discipline in Nursing, with the aim of providing an opportunity for a joint discussion of academic experiences in the realm of practice. The instructors of the discipline in which the proposal was developed also participated in the activities. The virtual technology gave new dynamism to the technique of field diary, making possible an exchange of experiences among the students, the instructor and the author, as well as moments of reflection and discussion regarding the themes faced in the Nursing practice.
\end{abstract} enfermagem.

\section{DESCRITORES}

Tecnologia educacional. Educação em enfermagem. Prática profissional.

\section{KEY WORDS}

Educational technology.

Education, nursing.

Professional practice.

\section{RESUMEN}

Este estudio describe una experiencia docente que tuvo como objetivo proporcionar la interactividad en la técnica del diario de campo, utilizando un ambiente virtual de aprendizaje. La propuesta educacional se originó en el Entrenamiento de Docencia, vinculado al Programa de Post Graduación Stricto Sensu en Enfermería de la Universidad Federal del Rio Grande do Sul (UFRGS) en la cual la académica, bajo la supervisión de su Profesora Orientadora, propuso la formación de grupos de discusión virtual para realizar el diario de campo en una disciplina de la graduación en enfermería con el fin de crear la oportunidad de discusión conjunta de las experiencias académicas en el campo de la práctica. Los profesores de la disciplina en la cual la propuesta fue desarrollada también estuvieron inseridos en las actividades. La tecnología virtual tornó dinámica la técnica de diario de campo, permitiendo el cambio de experiencias entre los académicos, el profesor y la estudiante, bien como momentos de reflexión y discusión sobre los temas confrontados en la práctica de enfermería.

\section{DESCRIPTORES}

Tecnología educacional. Educación en enfermería. Práctica profesional. 


\section{INTRODUÇÃO}

O Programa de Pós-Graduação Stricto Sensu em Enfermagem da Universidade Federal do Rio Grande do Sul (UFRGS) oferece aos mestrandos a oportunidade de se inserirem nas atividades docentes da graduação em enfermagem por meio da disciplina Estágio de Docência. Assim, o aluno do curso de mestrado tem a possibilidade de planejar e desenvolver atividades de ensino sob supervisão da orientadora do mestrado e aprovação do departamento ao qual a disciplina de interesse estiver vinculada. Dessa forma, tem-se um espaço para o futuro mestre em enfermagem desenvolver atividades docentes com base nos conhecimento teóricos sobre o processo de ensino-aprendizagem construídos nas disciplinas do curso de mestrado.

Na oportunidade de realizar o Estágio de Docência, almejou-se desenvolver atividades junto à Disciplina Fundamentos do Cuidado Humano III do curso de graduação em Enfermagem da Universidade Federal do Rio Grande do Sul, na qual ocorrem aulas teóricas, práticas em laboratório e campo hospitalar.

O diário de campo é uma técnica utilizada em pesquisas científicas e atividades acadêmicas, a fim de permitir o registro de observações e vivências em prol do avanço em diferentes áreas. Seguindo esta lógica, algumas disciplinas do Curso de Graduação da Escola de Enfermagem da UFRGS utilizam este método para o acompanhamento das atividades práticas de ensino-aprendizagem em campo prático, possibilitando aos professores acompanhar e avaliar as atividades desenvolvidas. Aos alunos, esta técnica possibilita a elaboração das experiências que constroem o saber do futuro profissional uma vez que o diário de campo representa mais do que um espaço para a descrição dos fatos, ele é um instrumento que estimula a reflexão contínua do aluno sobre o contexto onde as coisas acontecem, propiciando a leitura crítica sobre a realidade ${ }^{(1)}$.

Para a realização da técnica do diário de campo, planejouse desenvolver um ambiente de aprendizagem intera-tivo por meio de grupos de discussão (listservers). Esta é uma das ferramentas de aprendizagem mais utilizadas na categoria de tecnologias de ensino denominada Computer Mediated Comunication (CMC), assim como o correio eletrônico (e-mail), as conversações (chats), as informações hipermídia $(w w w)$, as bibliotecas virtuais, os jornais eletrônicos e as bases de dados. Recursos como estes estão sendo lentamente introduzidos no ensino de enfermagem, e ainda com pouca representatividade, embora sejam tecnologias que possibilitem maior flexibilidade, criatividade, dinamicidade, interação e comunicação no processo ensino-aprendizagem, estimulando a participação ativa do aluno ${ }^{(2)}$.
As trocas de mensagens, em grupos ou listas de discussão, fazem parte das comunicações virtuais assíncronas, ou seja, tratam-se de trocas que não acontecem em tempo real. $\mathrm{O} e$-mail enviado é postado de acordo com o endereço eletrônico da lista de discussão, a fim de ser distribuído aos demais participantes de forma a desencadear o compartilhamento por todos os inscritos na lista, caracterizando-a como um fórum de discussões em potencial. Os assuntos pré-estabelecidos, ou não, aglutinam-se em torno de interesses momentâneos, principalmente de grupos acadêmicos ou de trabalho ${ }^{(3)}$.

Conforme relatório elaborado em decorrência do Seminário Internacional sobre Universidades Virtuais na América Latina e Caribe, em 2003, com o uso das Novas Tecnologias de Informação e Comunicação, a intensificação tecnológica na educação enfatizou a disseminação da Internet. Dentre outras premissas, havia o desafio de promover maior interatividade entre alunos e professores, possibilitada pela tecnologia promotora de uma comunicação bidirecional e multidimencional, estabelecendo, assim, o enriquecimento da aprendizagem pelo uso de metodologias inovadoras ${ }^{(4)}$.

Além disso, o recurso em questão permite promover a individuação dos percursos de aprendizagem, personalizando a atenção oferecida aos alunos, respeitando características pessoais como o ritmo de aprendizado. Outra relevante questão apontada pelo relatório foi a busca para desenvolver a autonomia e a habilidade para o trabalho em grupo, características solicitadas pelo mercado de trabalho.

A partir de 1994 ocorre a expansão da internet junto às universidades de Ensino Superior Brasileiras. Com a publicação da Lei de Diretrizes e Bases para a Educação Nacional, oficializa-se em 1996, a modalidade de Ensino à Distância como válida e equivalente para todos os níveis de ensino, fazendo com que a universidade brasileira começasse a se dedicar ao uso de novas tecnologias para o ensino. Em 1997, universidades e centros de pesquisa públicos e privados completam o ciclo de aprendizado para gerar ambientes virtuais de aprendizagem, demarcando o nascimento da Universidade Virtual no Brasil. Por outro lado, o mesmo relatório aponta a inclusão digital como o principal desafio a ser enfrentado ${ }^{(4)}$.

No setor saúde, a utilização da informática iniciou na década de 70 com o uso de computadores em instituições hospitalares americanas. Esta aplicação, por sua vez, passou por um longo período de desenvolvimento que acompanhou as discussões mundiais sobre desenvolvimento tecnológico e aspectos éticos, ideológicos e financeiros ${ }^{(5)}$.

No que se refere à informática no ensino de enfermagem, em 1995, um autor ${ }^{(6)}$ já salientava dois aspectos distintos: o 
primeiro trata do ensino de enfermagem com o uso do computador enquanto recurso didático e o segundo se refere ao ensino da informática. Estes aspectos ainda hoje podem ser considerados incipientes na enfermagem uma vez que é pouco freqüente a presença desta temática nos currículos de enfermagem, da mesma forma como a utilização deste recurso para didática no ensino também pouco ultrapassa o auxílio a aulas expositivas.

Propondo-se a analisar a evolução da informática na saúde via divulgação científica no período de 1978 a 1998, um estudo $^{(5)}$ mostrou que nos últimos cinco anos o interesse aplicativo voltou-se ao ambiente de ensino, o que pode ser comprovado em publicação recente dos mesmos autores do estudo $^{(7)}$. Nesse estudo ${ }^{(5)}$, pôde ser vislumbrada mudança no perfil das pesquisas, que passaram de estudos teóricos para aplicações no ambiente de trabalho.

Considerando a relevância da temática e a evolução das novas tecnologias de informação e comunicação,

\begin{abstract}
é necessário que o professor valorize o diálogo, a troca, a relação interpessoal e acredite que se pode aprender dialogando, discutindo, trocando idéias. Se esses pressupostos não tiverem significância, o potencial da tecnologia não será reconhecido, perpetuando-se o modelo de ensino conservador e tradicional, descolado da realidade ${ }^{(2)}$.
\end{abstract}

Nesta perspectiva, utilizou-se o grupo de discussão como recurso para a elaboração dos diários de campo. Adotou-se esta técnica no intuito de acompanhar o processo de construção do conhecimento em enfermagem pela comunicação bidirecional com o aluno de graduação em seu primeiro contato com o ambiente hospitalar.

\section{MÉTODO}

O estágio de docência objetivou desenvolver uma proposta para o ensino de enfermagem por meio da ferramenta grupo de discussão, com a qual se pretendeu dar interatividade à técnica de diário de campo e proporcionar ambiente de discussão teórica-prática conjunta das vivências do campo prático na realização do diário de campo.

Para a realização desta atividade a Escola de Enfermagem da UFRGS conta com um laboratório de informática disponível aos alunos de graduação e pós-graduação, professores e enfermeiros que desenvolvam atividades vinculadas à unidade. Este laboratório é coordenado por uma professora adjunta da escola, com apoio de uma administradora da rede, uma bolsista de apoio técnico e uma monitora para auxílio dos usuários. Há 11 microcomputadores com internet disponíveis de acordo com o horário de funcionamento da escola, no entanto, o acesso ao grupo também pôde ser feito em domicílio.

A proposta do diário de campo virtual foi, primeiramente, apresentada pela mestranda e sua orientadora aos profes- sores da disciplina na qual a atividade ocorreria. A disciplina conta com ambiente de suporte para ensino-aprendizagem à distância pelo qual se realizam atividades através da Internet. Chamado de Teleduc, este projeto está sendo desenvolvido em conjunto ao Núcleo de Informática Aplicada à Educação (Nied) e pelo Instituto de Computação (IC) da Universidade Estadual de Campinas (Unicamp). Trata-se de um software livre que utiliza ferramentas de comunicação assíncronas e síncronas, como fórum, chat e e-mail (http//teleduc.nied.unicamp.br/teleduc/).

Tendo em vista o uso de ferramentas virtuais de aprendizagem pela disciplina na realização de um projeto construtivista de semiologia em ambiente virtual de aprendizagem, planejou-se associar a isso uma ferramenta de comunicação assíncrona para acompanhar o processo de ensino-aprendizagem em campo prático. Assim, as práticas em campo hospitalar foram acompanhadas de discussões e reflexões por meio de grupos de discussão (listservers).

A proposta foi apresentada a 48 alunos que cursavam a disciplina durante o desenvolvimento de conteúdos teóricos em sala-de-aula e, posteriormente, em aula prática ocorrida no laboratório de enfermagem, antecedendo a entrada ao campo hospitalar. Estes encontros ocorreram na busca de orientá-los sobre a dinâmica da atividade, o uso da ferramenta, bem como o objetivo de dar interatividade à técnica do diário de campo, proporcionando ambiente de discussão teórica-prática das vivências do campo prático. Ainda nesta oportunidade, buscou-se esclarecer o não benefício ou prejuízo da participação dos alunos na atividade, uma vez que poderiam abster-se da vinculação à proposta realizando o diário de campo na forma escrita e entregando ao professor.

Feita a divisão dos alunos em grupos para entrada no campo prático, conforme organização dos próprios alunos, contatou-se novamente com cada grupo para dar o início ao diário de campo por meio da discussão virtual. Desta maneira, formou-se um grupo de discussão para cada grupo de atividade prática. Utilizou-se a ferramenta e-group disponibilizado em site gratuito, exigindo da mestranda o preenchimento de requisitos que identificam o mediador/ mantenedor do grupo, o tipo de comunidade, a quem se destina e os endereços eletrônicos daqueles a quem o convite virtual seria enviado, ou seja, dos alunos.

Assim, concedeu-se um espaço exclusivo para cada grupo de prática, uma vez que cada um destes possuía um endereço eletrônico cujo acesso restringia-se aos alunos do grupo, professor do grupo e mestranda. Cada membro passou a receber todos os e-mails escritos pelos demais integrantes do seu grupo, e suas respostas também eram compartilhadas por todos.

O envolvimento dos professores da disciplina ocorreu conforme sua alocação no campo prático, pois cada professor fez parte de um grupo de discussão de acordo com o 
grupo ao qual seria responsável em campo prático. Assim, a tradicional entrega do diário de campo elaborado pelo aluno em folha de papel, como acontecia nesta disciplina, foi em grande parte substituída pelo diário de campo interativo ocorrido por meio da discussão virtual entre cada grupo.

Nesta discussão virtual, a mediadora buscou integrar os conteúdos teóricos da disciplina às atividades práticas descritas pelos alunos. Da mesma forma, os próprios alunos passaram a realizar a integração teoria-prática por meio da expressão de dúvidas que emergiram diante da vivência em campo. Os professores participaram comentando as atividades e ressaltando a relevância de algumas ações em detrimento dos conhecimentos construídos em sala-de-aula e laboratório e, ainda, na interface com a equipe de enfermagem da unidade hospitalar em que as práticas aconteceram.

A mediadora realizava sínteses das discussões e estimulava virtualmente a participação dos alunos e professores solicitando suas opiniões sobre o assunto. O conteúdo, bem como a periodicidade das discussões, variou principalmente conforme a interação dos membros de cada grupo. Embora fosse estimulada virtualmente a participação de todos, e também verbalmente pelo professor em campo prático, 16 alunos optaram pela realização do diário de campo na forma de relatório escrito em papel e 32 alunos participaram das atividades virtuais. A troca de mensagens iniciou no dia do reconhecimento do campo de prática e acompanhou o grupo até o encerramento das atividades neste local, perfazendo um total de 31 dias.

\section{APRESENTAÇÃOE DISCUSSÃO DA EXPERIÊNCIA}

A utilização dos grupos de discussão virtual foi uma experiência que possibilitou dar interatividade à técnica de diário de campo e proporcionar um ambiente de discussão teórica-prática conjunta das vivências do campo prático na realização deste diário. A relevância desta proposta para o ensino em enfermagem está na possibilidade de apreender variados aspectos que se inter-relacionam na vivên-cia acadêmica e, portanto, na formação do profissional de enfermagem.

O espaço oportunizado pelo grupo de discussão virtual foi ocupado, principalmente, para a troca de experiências através da descrição das atividades práticas realizadas pelos estudantes. Nestas, eram relatadas emoções de satisfação e/ou frustração que puderam ser compartilhadas entre os integrantes de cada grupo. A profissão de enfermagem impõe a execução de tarefas agradáveis ou repulsivas, havendo necessidade de um período de ajustes psíquicos internos para que a pessoa elabore defesas ou venha a obter satisfação com as atividades desempenhadas ${ }^{(8)}$.

Nas primeiras mensagens compartilhadas, pôde-se perceber as expectativas de cada um quanto às atividades pertinentes ao estágio, uma vez que se trata da primeira experi- ência destes acadêmicos com a enfermagem hospitalar. A relevância desta etapa para o aluno pôde ser identificada, principalmente, quando os estudantes atribuíam ao momento vivido expectativas de conhecer atividades inerentes ao enfermeiro, as quais eles diziam ser decisivas para os caminhos trilhados junto à profissão. Segundo um estudo ${ }^{(9)}$

ao atuar no campo prático o aluno planeja e executa assistência e desta atividade tira impressões e ocorrem internalizações, das quais formulam ou reformulam matrizes de aprendizagem.

No decorrer dos dias de prática e das comunicações nos grupos, puderam ser acompanhadas relações conflitivas no trabalho coletivo de produção de cuidados em saúde. Atitudes de profissionais médicos foram descritas no grupo virtual como inadequadas ao convívio interpessoal e, portanto, à qualidade do trabalho interdisciplinar. A posição de mediadora nas discussões do grupo permitiu à mestranda levantar hipóteses, questionar o posicionamento particular de cada um e estimular a reflexão, a fim de incentivar a formação de profissionais críticos.

O nível de ansiedade variou conforme características pessoais dos alunos e do grupo, ou seja, no relacionamento entre colegas e na relação professor-aluno. Em meio aos relatos sobre o dia-a-dia do campo prático foi possível perceber, durante a troca de $e$-mails, o entrosamento de cada grupo de estágio, assim como acompanhar a dinâmica das relações interpessoais estabelecidas entre os envolvidos, permitindo inclusive, identificar nas mensagens a motivação e o entusiasmo de cada grupo, assim como de seus membros.

Inúmeras vezes a ansiedade foi relatada como decorrente do medo de errar durante a realização de técnicas e procedimentos de enfermagem, principalmente, conforme os estudantes, quando não houvera a oportunidade de simular a atividade previamente em laboratório. A angústia foi descrita quando tentativas de punção venosa e sondagens foram experiências mal sucedidas, enquanto que os acertos foram associados à diminuição da ansiedade e à satisfação com o desencadeamento do estágio.

O medo de errar o procedimento ainda não realizado, a satisfação com a sucessão positiva de alguma ação técnica e a frustração com a falha foram descrições que acompanharam intensamente os diário de campo. Assim, por meio da interatividade proporcionada pelo ambiente virtual, estas ansiedades foram compartilhadas pelo grupo, o que estimulou a cooperação entre os alunos e professores de cada grupo diante das necessidades emergentes.

Em meio às vivências cotidianas, identificaram-se indícios da formação de concepções dos acadêmicos de enfermagem sobre a profissão. Os futuros enfermeiros colocaram suas expectativas nas tarefas desempenhadas no âmbito hospitalar como definições daquilo que é a enfermagem. 
Houve discussões que permearam questões como a interdependência no fazer em saúde, os desafios pessoais de se viver em regime de plantão e o desgaste físico e emocional do trabalhador de enfermagem.

Diante disso, a estratégia utilizada neste trabalho potencializou a reflexão destas vivências práticas pelo grupo, a intervenção do professor do campo ao indicar para o aluno os pontos cruciais a serem observados nas atividades diárias, bem como o conhecimento pelo professor das dificuldades enfrentadas pelos alunos em campo de prática.

Estes, dentre outros fatos, permitiram acompanhar de perto as vivências dos acadêmicos durante as práticas, assim como as repercussões destas na formação dos futuros enfermeiros. Desta forma, a experiência possibilitou utilizar a tecnologia como instrumento que permite a interatividade, a comunicação bidirecional e multidimencional, no sentido de atingir múltiplas dimensões do processo de construção do conhecimento em enfermagem.

Outro ponto positivo do espaço virtual oferecido pela comunidade criada foi a possibilidade de sanar dúvidas dos alunos e trocar informações, estabelecendo vínculo e o enriquecimento da aprendizagem pelo uso de uma técnica inovadora. Além disso, o recurso personalizou a atenção oferecida aos alunos, respeitando características pessoais de cada um. Sobre este aspecto, dois autores ${ }^{(10)}$ destacam que

muitas vezes, no exercício da docência, esquecemos de humanizar nossas relações com os alunos, que são uma réplica de nossos 'pacientes mais próximos', privando a eles e também a nós mesmos a oportunidade de experienciarmos o discurso que teoricamente defendemos.

Além disso, os participantes da comunidade virtual, voluntariamente, utilizaram a atividade como exercício de autoavaliação. Na descrição das atividades realizadas em campo de prática, os alunos avaliavam seu próprio desempenho, muitas vezes apontando seu crescimento diante conhecimento em enfermagem e/ou pontos que exigiam maiores investimentos. Assim, os resultados permitem visualizar muitas formas para fazer uso do recurso virtual na dinâmica do processo de formação de enfermeiros.

Encerrada a participação da mestranda, ficou a cargo de cada professor utilizar ou não a ferramenta com seu grupo de práticas. Na manutenção da proposta, os professores seriam os mediadores de seu próprio grupo e despenderiam

\section{REFERÊNCIAS}

1. Falkembach EMF. Diário de campo: um instrumento de reflexão. Contexto Educ (Ijuí).1987;7(2):19-24.

2. Peres HHC, Kurcgant P. O ser docente de enfermagem frente ao mundo da informática. Rev Lat Am Enferm. 2004;12(1):101-8. esforços no sentido do estímulo à participação dos alunos, bem como do domínio sobre a utilização da ferramenta para o esclarecimento aos mesmos.

Considera-se, ainda, o que foi apontado por autores ${ }^{(2)}$ no que tange o docente de enfermagem frente ao mundo da informática, pois os mesmos consideram a informática como um objeto imposto pela sociedade, havendo demonstrações de medo, insegurança e preconceito devido ao desconhecimento tecnológico, colocação já exposta em outro estudo ${ }^{(6)}$. A ação-inserção da informática no ensino da enfermagem é complexa e está interrelacionada com projetos pessoais dos docentes no desempenho de determinado papel social, bem como projetos mais amplos do contexto educacional ${ }^{(2)}$.

Tendo isso em vista, planejou-se novos encontros da mestranda com os professores da disciplina a fim de discutir e esclarecer a utilização da ferramenta como possibilidade para a realização do diário de campo que nesta experiência mostrou-se potencializar as funções do diário de campo.

\section{CONSIDERAÇÕES FINAIS}

A ferramenta utilizada atendeu ao objetivo de dar interatividade à técnica de diário de campo e proporcionar ambiente de discussão das vivências do campo prático na realização deste diário. Acompanhar as vivências da prática acadêmica por meio do grupo virtual possibilita ao docente uma aproximação com uma realidade permeada por receios, ansiedades, expectativas, percepções e concepções de forma interativa. A riqueza da proposta está na possibilidade do docente perceber a evolução do grupo por meio das impressões de seus atores principais, o que oferece detalhes por vezes não detectados em campo e que no uso do grupo de discussão potencializou-se pela troca dinâmica de informações entre cada grupo.

Mais do que isso, a atividade virtual também demonstrou novas possibilidades para o uso deste recurso no processo de ensino/aprendizagem. Além de propiciar o acompanhamento do estudante de enfermagem no seu primeiro contato com o ambiente hospitalar, a proposta para o ensino em enfermagem apresenta um meio de participar na consolidação das concepções dos futuros profissionais, uma vez que permite ao mediador/mantenedor e ao professor estimular reflexões e discussões acerca do fenômeno de conhecimento, tanto prático quanto teórico.

3. Estrázulas M. Interação e cooperação em Listas de Discussão. Infor Educ Teoria e Prática. 1999;2(2):81-6. 
4. Vianney J, Torres P, Silva EF. A Universidade Virtual no Brasil: os números do ensino superior à distância no país em 2002 [texto na Internet]. In: Seminário Internacional sobre Universidades Virtuais na América Latina e Caribe; 2003 fev. 13-14, Quito, Equador. [citado 2005 dez. 17]. Disponível em: http:// www.portaldeensino.com.br/ead_historico.pdf

5. Lopes MVO, Araújo TL. Processo de informatização em saúde: temas abordados em artigos publicados no período de 1978 e 1998. Rev Esc Enferm USP. 2002;36(1):25-32.

6. Marin HF. Informática em enfermagem. São Paulo: EPU; 1995.

7. Lopes MVO, Araújo TL. Avaliação de alunos e professores acerca do software "sinais vitais". Rev Esc Enferm USP. 2004;38(4):438-47.
8. Pitta A. Hospital: dor e morte como ofício. $3^{\text {a }}$ ed. São Paulo: Afiliada; 1994.

9. Lucchese R, Barros S. Grupo operativo como estratégia pedagógica em um curso de graduação em enfermagem: um continente para as vivências dos alunos quartanistas. Rev Esc Enferm USP. 2002;36(1):66-74.

10. Esperidião E, Munari DB. Holismo só na teoria: a trama de sentimentos do acadêmico de enfermagem sobre sua formação. Rev Esc Enferm USP. 2004;38(3):332-40. 